\title{
Conciencia, subjetivación y lucha. Análisis del concepto de lenguaje en La ideología alemana.
}

\author{
Consciousness, subjectivation and struggle. Analysis of the concept of \\ language in The German Ideology.
}

\author{
Por: Rodriguez, Néstor Emanuel Maximiliano." \\ Universidad Nacional del Nordeste \\ E-mail: rodriguezmaxi55@gmail.com
}

Fecha de recepción: 12/03/2021

Fecha de aprobación: 25/04/2021

DOI: http://dx.doi.org/10.30972/ach.065608

\section{Resumen}

El presente artículo pretende abordar la cuestión del "lenguaje" en La ideología alemana, su relación con la conciencia y la importancia de estos (lenguaje y conciencia) a la hora de hablar del proceso de subjetivación de la clase obrera en el sistema capitalista, planteando así al lenguaje como puente entre un sujeto y otro para 1) la satisfacción de sus necesidades materiales y 2) la subjetivación de cada uno de estos. Por otro lado, se trata también la problemática de la lucha existente entre el proletariado y la burguesía por adueñarse del signo y las consecuencias que se sucederían según cuál de estas clases sociales logre el dominio de la palabra y sus significaciones.

Palabras clave: Marx; Engels; Lenguaje; Conciencia; Lucha de clases.

\footnotetext{
* Este escrito surge en marco de la cátedra Seminario I: Análisis de una obra filosófica, dictada en la Facultad de Humanidades (UNNE) durante el año 2020.

${ }^{*}$ Estudiante del Profesorado en Filosofía
} 


\section{Abstract}

This article aims to address the question of language in The German Ideology, its relationship with consciousness and the importance of these (language and consciousness) when talking about the process of subjectivation of the working class in the capitalist system, thus posing language as a bridge between one subject and another for 1) the satisfaction of their material needs and 2) the subjectivation of each of these. On the other hand, the problem of the struggle between the proletariat and the bourgeoisie to take control of the sign and the consequences that will follow according to which of these social classes achieves the dominance of the word and its meanings.

Key words: Marx; Engels; Language; consciousness; Class struggle.

\section{Cómo citar este artículo:}

APA: Rodriguez, N. E. (2021). Conciencia, subjetivación y lucha. Análisis del concepto de lenguaje en La ideología alemana. Acheronta, № 6, 197-214. Recuperado de: (agregar dirección web)

\section{Introducción}

"El 'espíritu' nace ya tarado con la maldición de estar 'preñado' de materia, que aquí se manifiesta bajo la forma de capas de aire en movimiento, de sonidos, en una palabra, bajo la forma del lenguaje". Karl Marx - Friedrich Engels

"El discurso es un hecho social; no está autocontenido como una magnitud lingüistica abstracta, ni es posible derivarlo psicológicamente de la conciencia subjetiva del locutor considerada aisladamente". 
El presente escrito, producto de una investigación en base al libro La ideología alemana de Karl Marx y Friedrich Engels, se basa en la cuestión del lenguaje y su relación con la conciencia en la sociedad capitalista, tomando aportes de autores distintos tales como Paul Ricoeur hasta Valentín Volóshinov, centrándose en las distintas características y funciones que toma el lenguaje; con el objetivo de intentar mostrar, de esta manera, la dependencia existente entre las condiciones materiales de vida y la subjetividad de los trabajadores mediante la relación lenguaje-conciencia; además de revelar, también, el carácter de disputa que posee el lenguaje entre dos clases totalmente antagónicas como son el proletariado y la burguesía.

El escrito en cuestión se dividirá en cuatro partes que se relacionan entre sí pero que abordan temas ligeramente distintos (siempre en pos de la cuestión del lenguaje y la conciencia). Estas cuatros partes son:

1) El lenguaje y la conciencia en "La ideología alemana", donde se introducirá a las cuestiones principales sobre el lenguaje y la conciencia en el texto trabajado y abordando en este, a la vez, tres conceptos centrales: la relación entre lenguajeconciencia donde se planteará la idea de que el hecho de pensar es gracias y a través del lenguaje, el carácter colectivo del lenguaje donde se muestra cómo las significaciones de las palabras se deben a pertenecer o no a determinada clase social y el fundamento material del lenguaje, en el cual se plantea la idea de que el lenguaje se corresponde y significa con la realidad material misma.

2) El lenguaje en el proceso de subjetivación entre un yo y un Otro, donde se abordará la cuestión de la constitución del sujeto como tal en su relación, a través del lenguaje, con un Otro pero teniendo en cuenta a este sujeto (un yo) y a ese Otro como sujetos propios de la misma clase social, produciendo así también una conciencia de clase al reconocerse el sujeto-proletario con un Otro-proletario. Este apartado requiere mucha atención ya que trata un tema importante en la filosofía contemporánea: la constitución del sujeto, pero en base a una lectura marxista de la cuestión, donde el sujeto se conforma como tal y como sujeto social porque existe un 
Abril 2021.

ISSN 2344-9934

Otro que lo mira y lo nombra en un mismo contexto social, económico y político en el cual este yo se reconoce.

3) Intercambio, lucha y diálogo, parte del escrito en el cual se trabajará la cuestión de cómo cada determinada clase social significan las palabras de un modo diferente y como el lenguaje entra en disputa por estas significaciones. Es decir, se planteará y desarrollará la idea de que al ser uno solo el lenguaje, este necesariamente deviene en disputa debido a la lucha de clases política y lucha de clases lingüística donde el signo se convierte en arena de combate y ambas clases luchan por su apropiación en términos ideológicos. Se plantea además la cuestión de cómo, si la burguesía logra dominar la significación de las palabras, estas se vuelven neutras, es decir, carentes de todo el contexto social, económico y político que las hace surgir.

4) La alienación lingüística. En base a lo planteado por Ferruccio Rossi Landi (1970), aquí el tema de discusión sigue la línea del apartado anterior donde se parte desde la idea de que esta neutralización del lenguaje (y teniendo en cuenta la idea de “alienación" planteada por Marx y Engels en La ideología alemana) vuelve al sujetoproletario totalmente ajeno a ese lenguaje empañado ideológicamente por la burguesía, similar al extrañamiento producido por el proletariado y su trabajo en la sociedad capitalista donde esta actividad se vuelve un poder ajeno que lo condiciona. Cosa similar se plantea cuando se dice alienación lingüística; el lenguaje que se habla, al volverse neutro, se convierte en un poder ajeno que condiciona al sujeto que habla, influyendo esto también en la conciencia del mismo.

Una de las razones principales por las cuales se abordarán estas cuestiones es, sobre todo, la poca importancia que le dan Karl Marx y Friedrich Engels al problema del lenguaje en esta obra. La propuesta fundamental planteada aquí es poder, a partir de esta escasa participación ya mencionada, abordar nuevas problemáticas de índole filosóficas, políticas y sociales tales como las ya mencionadas anteriormente lucha de clases lingüística y alienación lingüística, generando así una ampliación de lo planteado en La ideología alemana en base a los aportes de otros autores, produciendo también 
así una nueva concepción teórica del concepto de "lenguaje" marxiano y sus relaciones con el capitalismo, el modo de producción y los sujetos.

\section{El lenguaje y la conciencia en La ideología alemana.}

Para comenzar con este escrito es preciso recalcar lo que Marx y Engels (1974), en su texto La ideología alemana, planteaban; estos decían que:

El lenguaje es tan viejo como la conciencia: el lenguaje es la conciencia práctica, la conciencia real, que existe también para los otros hombres y que, por tanto, comienza a existir también para mí mismo; y el lenguaje nace, como la conciencia, de la necesidad, de los apremios del intercambio con los demás hombres (p. 31).

Es a través de esta idea desde la cual se partirá para desarrollar este escrito, ya que aquí podemos visualizar tres cosas importantes: 1) que hay una cierta correlación entre lenguaje y conciencia, 2) que estas existen no solo para un individuo sino que poseen un carácter inter-individual y colectivo; y 3) estos -el lenguaje y la concienciaposeen un fundamento material, ya que tienen su origen desde la necesidad de intercambio, entre los sujetos reales de una sociedad, para la reproducción material de la vida.

Teniendo en cuenta la primera cuestión, es preciso hablar de la relación entre lenguaje y conciencia, ya que Marx y Engels, al hablar de estos, recalcan que surgen desde la necesidad de intercambio con un Otro. Esto nos lleva a pensar que el lenguaje funciona como puente para comunicarnos con un Otro ajeno a nosotros para poder satisfacer nuestras necesidades materiales. Ahora, el valor de la relación entre lenguaje-conciencia se encuentra en que el lenguaje, mediante las necesidades materiales, hace surgir a la conciencia, pero con el detalle de que esta conciencia es también lenguaje, y aquí reside su importancia. El hecho de pensar se da a través del lenguaje porque pensar no es más que pensar palabras, tal como nos dice Patrick Seriot (2020) cuando escribe que "el pensamiento no es más que las palabras, y las palabras son signos sociales, por lo tanto, todo pensamiento es un diálogo interior de palabras" (p. 11). Ahora, siguiendo la segunda cuestión planteada, podemos decir que 
este lenguaje que utilizamos no es un lenguaje individual propio de un solo sujeto, sino que es un lenguaje colectivo porque se forma en la relación misma que se da entre los sujetos para satisfacer sus necesidades. El lenguaje, como la conciencia, surge en y desde la comunidad que interactúa entre sí, entre los sujetos reales que hablan y se requieren para satisfacer sus necesidades mutuamente. Así, en el lenguaje y el habla "la elaboración (...) es individual, porque es considerada individualmente; pero el modelo de la elaboración es social" (Rossi Landi, 1970, p. 18). Asimismo, este autor anteriormente citado utiliza el concepto de habla común, y es este habla común lo que enmarca lo colectivo del lenguaje, el habla común corresponde a recurrir a los lugares habituales del lenguaje que se utilizan dentro de un determinado contexto o lugar pero recalcando que, justamente, esta habla se da y se forma de manera colectiva, aquí "se expresa el hecho de que el lenguaje, satisfaciendo necesidades sociales, es un instrumento ${ }^{1}$ no ya del individuo sino de la sociedad" (ibíd., p. 20). Esta idea del habla común también se relaciona con la idea de situación planteada por Seriot -a través de la lectura de Volóshinov, autor que se trabajará también en este escrito- donde cada miembro individual de un determinado grupo social se entiende debido a las similitudes políticas, económicas y sociales que atraviesan todos los que conforman ese grupo o esa clase, la situación "es el conjunto de lo que hay que conocer (los interlocutores, el contexto inmediato, su historia anterior, etc.) para comprender un enunciado" (Seriot, 2020, p. 15). ${ }^{2}$

Teniendo en cuenta todo esto, y volviendo a la cita mencionada al comienzo, es preciso recalcar otra vez que el lenguaje y la conciencia (que también es lenguaje) no es un hecho individual sino que funciona como puente hacia un Otro porque hay condiciones materiales que hacen posible que esto sea; en este caso: la necesidad de

\footnotetext{
${ }^{1}$ Cabe recalcar la denominación del lenguaje como instrumento porque aquí el lenguaje es justamente esto; una herramienta que sirve para comunicarnos con otros sujetos pero que a la vez se va formando a medida que el sujeto se hace a sí mismo. Sobre esto, Rossi Landi (1970) agrega que: "Discutir si se han formado primero los productos y los instrumentos físicos como extensiones del brazo, y las palabras como extensiones de la mente, es doblemente absurdo: porque ambas cosas se desarrollaron al mismo tiempo, y porque la mente, fenómeno social, es en sí misma esa doble extensión, se forma con ella" ( $p$. 21).

${ }^{2}$ Los conceptos de situación y habla común se retomaran más adelante en este escrito.
} 
intercambio. Ahora, teniendo en cuenta ya la tercera cuestión, estas condiciones materiales mencionadas anteriormente hacen surgir la idea de que el lenguaje tiene una base material que lo fundamenta, generando así también un puente entre sujeto, lenguaje y realidad, es decir, que el lenguaje no surge desde dentro hacia afuera, sino que el afuera -el mundo material- condiciona al lenguaje y al sujeto que habla, ya que el lenguaje y el habla son puramente obra y/o reflejo del mundo material. Para fundamentar esta cuestión es preciso traer a colación a Valentín Volóshinov (2009), que en su libro El marxismo y la filosofía del lenguaje nos plantea que:

La vivencia -lo expresado y su objetivación externa- están hechos, como ya sabemos, del mismo material. No hay vivencia fuera de su encarnación sígnica. Por consiguiente, desde un principio ni siquiera puede plantearse una diferencia cualitativa entre lo interno y lo externo. Pero es más que eso: el centro organizativo y formativo no se encuentra en el interior (es decir, no en el material de los signos), sino afuera (...).

En efecto, no importa qué aspecto de una expresión-enunciado tomáramos, este aspecto siempre se determina por las condiciones reales del enunciado en cuestión, y ante todo por la situación social inmediata (p. 136).

Así, el lenguaje y la realidad se corresponden mutuamente ya que el lenguaje, de alguna manera, refleja la realidad material porque está determinado por esta. Teniendo en cuenta esto, Paul Ricoeur (1999) plantea esta idea pero utilizando el término de mediación. El lenguaje es mediación entre el sujeto y la realidad porque la refleja y representa. La cuestión del lenguaje aquí se vuelve una cuestión ontológica ya que se da una apertura del lenguaje hacia el ser (Ricoeur, 1999; Rivara Kamaji, 2006) invirtiendo la idea heideggeriana de la apertura del ser al lenguaje (Heidegger, 2000) donde "el ser-ahí es ser-en-el-mundo y que el ser-en del ser-ahí es el mundo [por lo tanto] no hay necesidad de mediación ni de ninguna instancia que relacione al hombre con el mundo" (Rivara Kamaji, 2006, p. 109). La razón de esta inversión radica justamente en la justificación de que el lenguaje funcione como mediación ya que "si es el lenguaje el que se abre al ser y no viceversa, entonces el ser no se agota en el lenguaje, el ser no es únicamente lenguaje, por ello, Ricoeur podrá defender la 
Abril 2021.

existencia de "algo real extralingüístico'” (Ibíd. p. 107) y este algo real extralingüístico podemos plantearlo como no más que la realidad material misma. Por lo tanto, volviendo al planteamiento central, el lenguaje refleja algo real, refleja el mundo material propio de los sujetos que se relacionan entre sí. El lenguaje así, actúa como espejo del mundo, donde media entre el sujeto y la realidad porque hace referencia a algo concreto (una cosa) propio del mundo material para poder relacionarse con un Otro en pos del intercambio; es decir, funciona así como una triqueta entre el que dice (el sujeto que habla), [sobre] lo que se dice (algo del mundo material) y hacia quién se dice (un Otro). Sobre esto Volóshinov (como se citó en Montalbán Peregrín, 2011) también plantea algo similar cuando escribe que:

Cualquier enunciado en voz alta o escrito para su comunicación inteligible es la expresión y el producto de la interacción social de tres participantes: el locutor (el autor), el oyente (el lector) y el tema (el quien o qué) del habla (p. 272).

Entonces, a modo de conclusión de esta primer parte podemos decir que el lenguaje y la conciencia son un hecho social que responden a las condiciones materiales de la época en que se está, donde la necesidad de intercambio para vivir y sobrevivir hacen que el lenguaje ocupe el papel tan importante de mediador (o puente) entre los sujetos y el mundo material, pero sobre todo entre los sujetos mismos, es decir, entre un yo y un Otro para satisfacer sus necesidades materiales. Ahora, podemos caracterizar a esta primera función del lenguaje como política o material, pero ¿existe otra forma de mediación entre un yo y un Otro a través del lenguaje?

\section{El lenguaje en el proceso de subjetivación entre un yo y un Otro.}

Anteriormente se planteó, desde la perspectiva marxiana, que el lenguaje funciona como un puente entre un sujeto y un Otro para satisfacer sus necesidades de reproducción de vida material, esta puede considerarse, justamente, como una función material del lenguaje. Ahora, es preciso plantear que los sujetos mismos que utilizan el lenguaje como puente no son sujetos acabados, sino que a la vez y a medida 
que se relacionan entre sí, van conformando su subjetividad. Aquí se abre otra característica del lenguaje como puente porque no solo funciona para satisfacer las necesidades de la comunidad sino que también para la conformación de cada sujeto individual como tal. Aquí el Otro toma un papel fundamental porque a medida que un yo se relaciona con un Otro, este lo condiciona y forma su subjetividad, a la vez que también el yo lo hace con la de ese Otro. Volviendo a Ferruccio Rossi Landi (1970), este nos dice que:

Cuando se habla de la necesidad de relaciones de un hombre con otros hombres, no quiere decirse con ello que todos esos hombres ya estén formados. Estos se forman, en cambio, precisamente en el proceso de la institución de aquellas relaciones (p. 15).

El sujeto mismo que utiliza el lenguaje para relacionarse con un Otro es, a la vez, un sujeto en construcción; y desde una línea marxiana podríamos decir que el ser humano es un ser social y en este ser social el sujeto encuentra su realización. Por lo tanto, es con la mirada de un Otro que el sujeto se va formando a sí mismo; y a la vez, este sujeto y el Otro no se encuentran sino en el mundo material, por lo que la subjetivación del propio sujeto se debe también no solo a un Otro sino a la existencia social de ambos, "el sujeto abandona el territorio clásico de la intemporalidad para situarse en la historia" (Terol Rojo, 2013, p. 283), es decir, situarse en la realidad material conformada por individuos reales que nos miran y son mirados. Es en el discurso del Otro donde el yo se constituye y se forma, es a través de la mirada del Otro donde un sujeto puede verse y reconocerse como tal porque, si bien el sujeto actúa y tiene una idea de sí mismo, es también el discurso y la mirada del Otro el que lo ayuda a interpretarse y conocerse. Sobre esta relación discursiva entre el yo y el Otro, Volóshinov (2009) ya nos planteaba estas cuestiones en la Rusia soviética: primero que la relación discursiva se da entre dos sujetos que existen un contexto material y social determinado ${ }^{3}$; y segundo que, como ya mencionamos, en el Otro el

\footnotetext{
3 "Esto sucede porque se construye entre dos personas socialmente organizadas, y aunque un interlocutor real no exista, siempre se prefigura como una especie de representante del grupo social al que el hablante pertenece. La palabra está orientada a un interlocutor, hacia la condición de éste: si se trata de la persona perteneciente a un mismo grupo social o no, si está por encima o por debajo del hablante (rango jerárquico del interlocutor), si está o no relacionado con el hablante mediante algún
} 
sujeto se reconoce a sí mismo ya que el lenguaje funciona como un puente, pero esta vez no ya de una manera material sino más bien abstracta. Este autor nos dice:

La palabra representa un acto bilateral. Se determina en la misma medida por aquel a quien pertenece y por aquel a quien está destinada. En cuanto palabra, aparece precisamente como producto de las interrelaciones del hablante y el oyente. Toda palabra expresa a "una persona" en su relación con "la otra". En la palabra me doy forma a mí mismo desde el punto de vista del otro, al fin de cuentas desde el punto de vista de mi colectividad. La palabra es el puente construido entre el yo y el otro. Si un extremo del puente está apoyado en mí, el otro se apoya en mi interlocutor. La palabra es el territorio común compartido por el hablante y su interlocutor (p. 137).

Ahora bien -y teniendo en cuenta todo esto-, podemos decir entonces que el sujeto social se construye como sujeto y sobre todo como sujeto social en pos de su relación con un Otro, pero con base en la realidad material existente; es decir, la base material sobre la que se funda la conciencia y el lenguaje; ya que tanto el sujeto (un yo) y el Otro viven sobre una estructura específica, es decir, un sistema y una condiciones económicas determinadas que luego hacen surgir los demás componentes que también (además de la relación con un Otro) construyen la conciencia del sujeto; tales como "las formas jurídicas, políticas, religiosas, artísticas o filosóficas, en suma, ideológicas" (Marx, 2008, p. 5).

Es decir, entonces, que la importancia del lenguaje no radica solo en su función política de intercambio material sino también en su función dialógica entre dos sujetos que dentro de esa relación se constituyen como tales. Un sujeto (un yo) se subjetiva en parte-, a medida que interactúa con un Otro, a través del discurso de ese Otro; funcionando así el lenguaje como un puente entre estos que si bien, como ya mencionamos, surge de la necesidad de intercambio material, también funciona como un elemento clave en el proceso de subjetivación y la conformación de la conciencia de clase porque, al vernos a nosotros mismos gracias a la mirada de un Otro de la misma

vínculo social más estrecho (...). Un interlocutor abstracto, esto es, un hombre en sí, no puede existir; con este, en efecto, no tendríamos ningún lenguaje común en sentido literal ni figurado" (Volóshinov, 2009, pp. 136-137). 
clase social nos reconocemos también como pertenecientes a esa clase, es decir, la clase proletaria donde el sujeto y el Otro viven y se relacionan (Montalbán Peregrín, $2011)^{4}$.

\section{Intercambio, lucha y diálogo.}

En este tercer apartado nos enfocaremos y volveremos sobre los conceptos de habla común y situación planteados por Rossi Landi (1970) y Patrick Seriot (2020). Cuando decimos "habla común", como ya sugerimos, se hace referencia al conjunto de elementos que utiliza un determinado grupo social para comunicarse. Cuando hablamos de "situación" hacemos referencia al contexto social, económico y político en que viven y comparten entre sí ciertos sujetos y cómo esto los habilita para una determinada forma de comunicarse entre ellos. Ahora, si en vez de grupo social hablamos de clase social, podemos entender entonces que es una determinada clase social la que comparte el mismo contexto con todos sus individuos, de esta manera "el contenido del componente verbal de la conducta, está determinado en todos sus aspectos fundamentales y esenciales por factores sociales objetivos; así el discurso, lo verbal no es propiedad de un sujeto sino de su grupo social" (Montalbán Peregrín, 2011, p. 273). Es así que, por ejemplo, "un intercambio social en la fábrica se hace entre pares, nunca entre obreros y capataz. La 'situación' es más un lugar del espacio interindividual que lugar de fuerzas en oposición" (Seriot, 2020, p. 15). Entonces, el intercambio lingüístico entre un yo y un Otro solo se da a través de los miembros de la misma clase porque cada uno conoce y es consciente de su situación. Por lo tanto, y volcándonos en el terreno de la lucha de clases, un "entendimiento" entre el proletariado y la burguesía sería imposible ya que, al ser clases sociales antagónicas, cada una vive en situaciones diferentes y no comparten las mismas necesidades de reproducción material.

\footnotetext{
4 “Al tomar conciencia de uno mismo, tratamos de vernos a través de los ojos de otra persona, de otro representante del grupo o clase social. De este modo, la autoconciencia siempre nos lleva a la conciencia de clase, de la cual es reflejo y especificación en sus aspectos fundamentales y esenciales" (Montalbán Peregrín, 2011, p. 273).
} 
Lo que sí hay con la burguesía es lucha, pero no diálogo. Ahora ¿es la lucha la consecuencia de no haber diálogo? ¿O es la causa? Esto resulta difícil de responder, pero la mejor opción no equivaldría ni a una ni a la otra. Es positivo que haya lucha porque es necesaria, ya que "la historia de todas las sociedades anteriores a la nuestra es la historia de luchas de clases" (Marx y Engels, 2014, p. 315) y además, porque 1) no se vive en las mismas situaciones y 2) el diálogo llevaría a una conciliación con la burguesía; y esto es lo peor que le puede ocurrir a la clase trabajadora. La conciliación es imposible porque la explotación, la diferencia y la desigualdad van a continuar. Además, recordemos que la idea central del marxismo es que la clase obrera se haga con el poder, no someterse o entregarse a la clase explotadora. Tal como plantean Marx y Engels (1974) en La ideología alemana:

Sólo los proletarios (...) totalmente excluidos del ejercicio de su propia actividad, se hallan en condiciones de hacer valer su propia actividad, íntegra y no limitada, consistente en la apropiación de una totalidad de fuerzas productivas y en el consiguiente desarrollo de una totalidad de capacidades (p. 79).

Ahora bien, teniendo en cuesta esto, a la lucha de clases tradicional planteada por el marxismo podemos compararla y unirla con el término de lucha de clases lingüística. Esta lucha lingüística que se establece entre la burguesía y el proletariado debido a las diferentes situaciones, planteadas por Seriot (2020) siguiendo la línea de Volóshinov, es producto no de la existencia de un lenguaje proletario y otro burgués, sino de la existencia misma de un solo lenguaje, un solo signo que es utilizado por ambos, cada uno desde su posición. Es por esto que "el signo llega a ser la arena de la lucha de clases" (Volóshinov, 2009, p. 47). El leguaje aquí deja de ser utilizado como puente y empieza a ser utilizado como arena de lucha, lugar de conflicto donde distintos intereses entran en pugna. ${ }^{5}$ El signo pasa a ser propiedad de quien lo posea y lo hegemonice (problemática que se tratará un poco más adelante). Teniendo en cuenta esto, García de León (1985) escribe:

\footnotetext{
5 "El signo es ya una interpretación, es un tejido de interpretaciones, toda verdad encubre una interpretación, una determinada voluntad" (Cruz, 2006, p. 186).
} 
La solución no es elaborar diccionarios diferentes para clases (...) sino irse al fondo de la cuestión: la determinación de cuáles son los procesos de multiacentualidad de la palabra, de tema o carga semántica, que dependen del lugar que se ocupe en la sociedad (p. 73).

De esta manera, el lenguaje, su capacidad de enunciación y su significación es de quién pueda poseerlo ${ }^{6}$. Teniendo en cuenta esto, podemos hablar ahora de la lucha por parte de la burguesía para imponer su ideología, es decir, la ideología dominante. Para esto hay que tener presente la idea de alienación de Marx y cómo ésta se presenta. Dicho esto, podemos decir que la alienación en Marx aparece como un poder ajeno que nos determina como individuos y que se da a través de la división del trabajo y la fijación de un sujeto en una actividad determinada por la existencia de un modo de producción específico que hace posible esto, condicionando así qué actividades puede realizar un sujeto y cuales no (Marx, 1974). Ahora, este poder ajeno también lo podemos ver en el lenguaje, produciendo así una alienación lingüística (Rossi Landi, 1970).

\section{La alienación lingüística.}

Este tipo de alienación se da cuando el sujeto que habla es determinado por el lenguaje mismo que habita y lo habla, es decir, esto que al parecer brota de uno mismo es a la vez un producto ajeno y extraño que opera dentro del sujeto y lo condiciona a la hora de enunciar algo. Así como el sistema productivo condiciona y determina al sujeto no dejándolo elegir sus actividades, el sistema lingüístico con el que el sujeto se comunica también determina la manera en que este se expresa. Sobre esto, Rossi Landi (1970) escribe lo siguiente:

\footnotetext{
6 "La existencia reflejada en el signo no tanto se refleja propiamente como se refracta en él. ¿Qué es lo que determina la refracción del ser un signo ideológico? Es la intersección de los intereses sociales de orientación más diversa, dentro de los límites de un mismo colectivo semiótico; esto es, la lucha de clases. (...) Así las distintas clases sociales usan una misma lengua. Como consecuencia, en cada signo ideológico se cruzan los acentos de orientaciones diversas" (Volóshinov, 2009, p. 47).
} 
Como repetidor de modelos obligatorios o supra-personales, el obrero lingüístico se halla en la situación de no saber qué hace cuando habla, de no saber por qué habla cómo habla, y de pertenecer a procesos de producción lingüística que lo condicionan desde el principio, que lo obligan a ver el mundo de una manera determinada y que le dificultan el trabajo original (p. 55).

Siguiendo esta idea de alienación lingüística, del lenguaje como algo ajeno al sujeto -al obrero-, Volóshinov (2009) plantea que la burguesía lo que quiere es adjudicar al signo un "carácter eterno por fuera de las clases sociales" (p. 48), es decir, volverlo ajeno, algo abstracto y separado del sujeto ${ }^{7}$; en otras palabras, negar la contextualidad histórica, social y política del lenguaje, la condición material que permite el intercambio lingüístico entre los miembros de una sociedad, neutralizarlo. Esta acción de la burguesía planteada por Volóshinov podemos entenderla desde una posición althusseriana, donde la imposición del lenguaje como neutro funciona como obra del aparato ideológico del Estado (Althusser, 2003), ya que se trata de instaurar la ideología dominante a través de la neutralización del signo y, a la vez, si es que sucede (si se neutraliza el lenguaje y se lo entiende como algo por fuera de las clases sociales y su lucha) y de alguna manera se lo cuestiona o disputa, acarrea una represión simbólica -que en este caso es lingüística pero represión en fin-. Para aclarar mejor esta idea podemos volver a Rossi Landi (1970) cuando plantea que:

El hablante, por así decir, es llamado al servicio por la sociedad en que nace: se le pide e impone erogar su fuerza de trabajo lingüístico y se le enseñan obligatoriamente las modalidades de la erogación: debe usar productos ya existentes, consumirlos reproduciéndolos inconscientemente según modelos que de tal manera son confirmados y perpetrados. Aun cuando logre rechazar tales modelos, la pena que debe pagar consiste ni más ni menos que en la expulsión de la sociedad lingüística: no aprendiendo a hablar, o hablando un lenguaje desviado personalmente, ya no es entendido ni logra hacerse entender. Es la muerte lingüística o muerte comunicativa (p. 54).

\footnotetext{
7 “Es sobre todo la clase dominante la que se esfuerza por impartir al signo ideológico un carácter que no tiene ni tendrá: eterno, neutral, por encima de las clases (...)" (García de León, 1985, p. 74).
} 
Es importante tener en cuenta esta alienación lingüística ya que si volvemos sobre una de las ideas planteadas al comienzo de este escrito -sobre la relación que hay entre el lenguaje y la conciencia ya que el hecho mismo de pensar se da a través del lenguaje, es decir, pensar es pensar (en y con) palabras-, la neutralización del signo, la descontextualización social de la palabra acarrearía una notable influencia en la conciencia misma de los trabajadores, ya que estos, sumergidos en un lenguaje dominado por la burguesía, no se pensarían a sí mismos desde su condición sino desde la condición burguesa que estaría presente implícitamente en el lenguaje mismo con el que se piensa. Quizá el primer paso necesario para poder pensarse como trabajadores explotados es entender que el lenguaje mismo con el que se piensa es producto del modo de producción de la época y del contexto social en el que se está, pero sin perder de vista la idea de que este mismo leguaje es un lugar de combate por su apropiación ideológica entre los trabajadores y la burguesía. El hecho de neutralizar el lenguaje también neutralizaría la conciencia, la llevaría a un lugar por fuera de las clases sociales, generando así una falsa conciencia y una alienación porque: primero que el trabajador se pensaría a sí mismo desde un lenguaje con carga ideológicamente burguesa; y segundo, porque este lenguaje, como ya planteamos, se vuelve totalmente ajeno al trabajador porque está por fuera de las clases sociales y el mismo termina condicionándolo a la hora de pensar y hablar; por lo que es necesario entender al lenguaje como producto mismo de las relaciones de producción y, como planteaban Marx y Engels, como un instrumento que sirve para el intercambio con los demás sujetos. Sobre todo esto, Montalbán Peregrín (2011) escribe que:

La "alienación" se convierte en concepto esencial para intentar comprender la conciencia de los trabajadores en la sociedad capitalista, considerando como raíz material de la misma el hecho de que la actividad del propio trabajador está separada de éste, como algo ajeno a sí mismo, eternizando de ese modo la pasividad y la resignación como los sentimientos clave de un orden inalterable. La posibilidad de cambio del statu quo pasaría, como precondición para cualquier intención revolucionaria, por la propia transformación de la colectividad laboral en masa activa, lo que inevitablemente conlleva también la transformación de la conciencia de la clase trabajadora (p. 265). 
De esta manera y para finalizar, se puede plantear que la lucha de clases llevada al plano lingüístico- es una pelea que tiene que darse, donde la lucha es en el lenguaje mismo ligado a los intereses de cada clase social, es decir, una pelea por la significación de las palabras y del signo ya que, recordando lo que planteaba Volóshinov (2009), el signo es la arena de la lucha de clases.

\section{Conclusión.}

A modo de cierre, y teniendo en cuenta cada temática desarrollada, podemos llegar a la conclusión de que el lenguaje puede funcionar de diversas maneras. Puede ser un puente entre un sujeto y otro para la reproducción material y la satisfacción de necesidades, puede ser también un puente entre un sujeto y un Otro pero para el proceso de subjetivación de ambos, donde un yo se reconoce como tal gracias a un Otro que lo mira y lo nombra. Puede también el lenguaje ser un lugar de lucha, donde el proletariado y la burguesía se enfrentan por la significación de las palabras, influyendo esta significación luego en la conciencia; ya que, si la burguesía logra su supremacía en el lenguaje por sobre el proletariado, esta lo volvería neutro, carente de todo contexto social, lo que produciría el mismo efecto en la conciencia del trabajador, donde al tener incorporado un lenguaje neutro, este pensaría (y se pensaría) a partir de esa neutralidad, quitando toda posibilidad de tener una conciencia de clase. Razón por la cual es importante la lucha ideológica del lenguaje, ya que si se lo vuelve carente de contexto social, económico y político, el proletariado quedaría sumergido en esta neutralidad, en esta alienación lingüística sin la capacidad de pensar y entender al lenguaje y la conciencia dentro de un sistema capitalista y una división de clases en el cual se está arrojado y en el cual es necesario luchar para llegar al poder y acabar así con toda explotación del ser humano por el ser humano.

Al ser el lenguaje el reflejo de la realidad material y funcionar como puente para la satisfacción de necesidades en esta realidad material y como puente, también, para la subjetivación, es importante poder estudiarla desde esta perspectiva marxiana, donde los conceptos de lucha de clases lingüística y alienación lingüística puede 
resultar de gran ayuda para comprender el sistema en que se está inmerso y la clase a la que se pertenece. Comprender al lenguaje como un lugar de disputa donde cada palabra que se diga posee una carga ideológica que surge desde un contexto material específico es importante para luego pensar-se desde allí. Utilizar el lenguaje como vía para la conciencia de clase, donde un yo-proletario se reconoce como tal en y gracias a un Otro-proletario que lo mira y lo nombra, deshaciendo así todo velo de neutralización que se intenta imponer por parte de la clase dominante.

Si partimos de que pensar es pensar palabras, debemos entender también que estas palabras están cargadas de contexto, al igual que el sujeto que las dice y las piensa, por lo que es importante no permitir que el lenguaje se vuelva ajeno a las clases sociales porque de allí surgen y allí toman forma, entre los sujetos que hablan y se relacionan, los sujetos que sobreviven en el mundo material y que se constituyen como tales en él. El lenguaje es en y gracias al mundo material y los sujetos que lo conforman, y parafraseando -y contrariando- a Nietzsche (1996), el origen del lenguaje no procede de las nubes sino de las cosas mismas, del mundo material y de los sujetos.

\section{Bibliografía:}

- Althusser, L. (2003). Ideología y aparatos ideológicos del Estado. (J. Sazbón y A. J. Pla, Trad.). En: Ideología y aparatos ideológicos del Estado. Freud y Lacan. Buenos Aires, Argentina: Ediciones Nueva Visión.

- Cruz, J. I. (2006). El pensamiento de Michel Foucault como caja de herramientas. Discusiones Filosóficas N 10, pp.: $183-198$.

- García de León, A. (1985). El poder de los caminos del lenguaje. Cuadernos Políticos $\mathrm{N}^{\circ} 44$, pp.: $67-81$.

- Heidegger, M. (2000). Carta sobre el humanismo. (H. Cortés y A. Leyte, Trad.). Madrid, España: Alianza.

- Marx, K. (2008). Contribución a la crítica de la economía política. (J. Tula; L. Mames; P. Scaron; M. Mumis y J. Aricó, Trad.). México: Siglo XXI editores.

- Marx, K. y Engels, F. (1974). La ideología alemana. (W. Roces, Trad.). Montevideo y Barcelona: Pueblos Unidos y Grijalbo. 
- Marx, K. y Engels. F. (2014) Manifiesto del Partido Comunista. (J. Muñoz, Trad.). En: Marx. Colección Grandes Pensadores. Barcelona, España: Gredos.

- Montalbán Peregrín, F. M. (2011). Diálogo entre marxismo y psicoanálisis: vigencia del legado de V. N. Voloshinov. Universitas Psychologica V. $10 \mathrm{~N}^{\circ} 1$, pp.: $263-$ 277.

- Nietzsche, F. (1996). Sobre verdad y mentira en sentido extramoral. (L. Valdés, Trad.). Madrid: Tecnos.

- Ricoeur, P. (1999). Filosofía y lenguaje. (G. Aranzueque Sahuquillo, Trad.). En: Historia y narratividad. Barcelona, España: Paidós e I.C.E.-U.A.B.

- Rivara Kamaji, G. (2006). El problema lenguaje-realidad en Paul Ricoeur. En: Weber, P. (coor.) Cuestiones hermenéuticas: de Nietzsche a Gadamer (pp. 105-114). México: Editorial Itaca.

- Rossi Landi, F. (1970). El lenguaje como trabajo y como mercado. Caracas, Venezuela: Ávila Editores.

- Seriot, P. (2020). Vološinov, el materialismo y la filosofía marxista del lenguaje. Pensamientos al margen. Revista digital de ideas políticas $\mathrm{N}^{\circ} 12$, pp.: 2 - 19.

- Terol Rojo, G. (2013). Lecturas de la crítica foucaultiana a la subjetividad. Thémata. $\mathrm{N}^{\circ}$ 47, pp.: 273-300

- Volóshinov, V. (2009). El marxismo y la filosofía del lenguaje. (T. Bubnova, Trad.). Buenos Aires, Argentina: Ediciones Godot. 